\title{
Insulin and vanadate restore decreased plasma endothelin concentrations and exaggerated vascular responses to normal in the streptozotocin diabetic rat
}

\author{
R.L. Hopfner, D. Misurski, T. W. Wilson, J. R. McNeill, V. Gopalakrishnan \\ Department of Pharmacology and the Cardiovascular Risk Factor Reduction Unit (CRFRU), College of Medicine, \\ University of Saskatchewan, Saskatoon, Saskatchewan, Canada
}

\begin{abstract}
Summary Although insulin has been shown to raise plasma concentrations of endothelin (ET) and up regulate vascular smooth muscle $\mathrm{ET}_{\mathrm{A}}$ receptor expression, the interaction of vanadate, an insulinomimetic agent, with the vascular ET system has not been investigated. We compared the effects of oral vanadate treatment $(0.5 \mathrm{mg} / \mathrm{ml}$; p.o. $)$ and insulin infusion $\left(12 \mathrm{mU} \cdot \mathrm{kg}^{-1} \cdot \mathrm{min}^{-1}\right.$ s.c.) for two weeks on plasma ET concentrations and vascular responses to endothelin-1 (ET-1) and the $\alpha_{-1}$ adrenoceptor agonist, methoxamine, in aortic ring preparations from streptozotocin (STZ) diabetic and non-diabetic adult male Sprague-Dawley rats. Plasma ET concentrations were lower $(p<0.01)$ in STZ diabetic rats compared with normal control rats. Insulin and vanadate treatment restored plasma ET to normal $(p<0.01)$ in STZ rats and increased ET concentrations in the control $(p<0.05)$ group. Higher maximal tension responses to both ET-1 $(p<0.01)$ and methoxamine
\end{abstract}

$(p<0.05)$ were present in STZ rats in both endothelium intact and denuded aortic preparations compared with the control group. Both insulin and vanadate treatment returned these responses to normal. It is concluded that low plasma concentrations of insulin and high plasma glucose in STZ diabetic rats are accompanied by lower concentrations of plasma ET. Insulin and vanadate treatment restores diminished plasma ET to control concentrations and attenuates exaggerated agonist(s)-evoked vascular smooth muscle responses in STZ-induced diabetic rats. In addition to well known beneficial metabolic effects, insulin and vanadate may beneficially affect cardiovascular regulation in the STZ diabetic rat by correcting abnormal ET activity. [Diabetologia (1998) 41: 12331240]

Keywords Aorta, endothelin, insulin, streptozotocin diabetic rat, vanadate.
Type I (insulin-dependent) diabetes mellitus is associated with metabolic and cardiovascular abnormalities as exemplified by the streptozotocin (STZ) in-

Received: 22 January 1998 and in final revised form: 25 May 1998

Corresponding author: Professor V. Gopalakrishnan, Ph.D., Department of Pharmacology and the CRFRU, College of Medicine, University of Saskatchewan, Saskatoon, SK. S7N 5E5 Canada

Abbreviations: $\mathrm{EC}_{50}$, Agonist concentration producing $50 \%$ of maximum response; $\mathrm{E}_{\max }$, maximum response; $\mathrm{EC}$, endothelial cells; EDRF, endothelium derived relaxing factor; ET, endothelin; NO, nitric oxide; SD, Sprague-Dawley rat; STZ, streptozotocin. duced diabetic rat. Along with profound hyperglycaemia and reduced plasma insulin concentrations, STZ rats shaw altered responses to vasoconstrictor stimuli, and over time, develop complications characteristic of Type I diabetes [1]. Endothelin has been implicated in various disorders such as renal disease, atherosclerosis, diabetes mellitus and hypertension [2-6]. The STZ diabetic rat has been shown to exhibit either attenuated or enhanced vascular responses to various agonists, including endothelin (ET) [7-17]. In addition, some studies have shown plasma ET concentrations to be increased in both STZ rats and in patients with Type I diabetes [4, 15, 17-19] and other studies demonstrated decreased or unchanged plasma ET concentrations in diabetic models compared with non-diabetic control subjects [20-22]. The rea- 
sons for these discrepancies are not well defined, but nevertheless, both human and animal models of Type I diabetes appear to exhibit alterations in vascular ET activity. Clearly, more studies are warranted to clarify this issue.

Insulin has been shown to increase ET release from endothelial cells (EC) [23, 24], and to increase plasma ET levels in humans [25, 26]. Furthermore, we and others have shown that insulin increases ET receptor expression and action in isolated vascular smooth muscle cells $[27,28]$. Despite such potentially adverse vascular effects of insulin mediated by the ET system, cardiovascular morbidity is decreased when tight glycaemic control is instituted with insulin therapy [29]. Vanadium compounds have also been shown to exhibit beneficial metabolic effects and to correct alterations associated with the diabetic state in STZ rats $[14,30]$. The effect of vanadate treatment on alterations in ET activity in diabetes has not been investigated. Therefore, we investigated the effect of 2 weeks of vanadate treatment on ET-1 evoked tension responses and plasma ET concentrations in STZ diabetic rats. In light of the well documented effects of insulin on the vascular ET system, we compared the effects of vanadate with those of insulin over the same treatment period.

\section{Materials and methods}

Animals. Sprague-Dawley (SD) rats (nine weeks old and 150-200 g) were fasted for $24 \mathrm{~h}$ before being given either a single dose of streptozotocin (STZ group) $(55 \mathrm{mg} / \mathrm{kg})$ in citrate buffer ( $\mathrm{pH} 4.5$ ) or citrate buffer (vehicle) alone (SD group) via intraperitoneal injection. Hyperglycaemia $(>15 \mathrm{mmol} / \mathrm{l})$ was confirmed in the treated rats after 1 week. At 3 weeks after STZ treatment, rats were divided into eight groups of eight rats each: SD-insulin control, SD-insulin treated, STZ-insulin control, STZ-insulin treated, SD-vanadate control, SD-vanadate treated, STZ-vanadate control and STZ-vanadate treated. Rats in the insulin and insulin control group received either $12 \mathrm{mU} \cdot \mathrm{kg}^{-1} \cdot \mathrm{min}^{-1}$ of Iletin II insulin or sterile diluent via subcutaneous miniosmotic pump (ALZA Corp., Palo Alto, Calif., USA) for 2 weeks. Vanadate treated rats received $0.5 \mathrm{mg} / \mathrm{ml}$ sodium orthovanadate (buffered to $\mathrm{pH} 7.0$ with ascorbic acid) in drinking water freshly prepared every second day for 2 weeks, whereas normal control rats received plain tap water. Animals were weighed before and after treatment and food and water intake was monitored daily over the treatment period. Vanadate doses were gradually increased over the week preceding the study to allow the rats to become accustomed to the taste.

Analytical procedures. At the end of the 2 week treatment period, animals were killed by decapitation under ether anesthesia and plasma samples were collected in tubes containing EDTA. Blood samples were centrifuged at $2000 \mathrm{~g} \times 10 \mathrm{~min}$ and stored at $-70^{\circ} \mathrm{C}$ until plasma insulin and ET measurements were undertaken. Plasma glucose was measured on the day of sacrifice by glucose oxidase method (One Touch, Lifescan, Vancouver, Brit. Col., Canada), and plasma insulin and ET were measured using commercially available radioimmu- noassay kits (Amersham, Oakville, Ont., Canada). Briefly, sample preparation for plasma ET determinations was done by first acidifying $1 \mathrm{ml}$ of plasma with $2 \mathrm{~mol} / \mathrm{l} \mathrm{HCl}$ and centrifuging at $1000 \mathrm{~g} \times 5 \mathrm{~min}$. The sample was then loaded onto Amprep 500 mg C2 mini-columns (Amersham), washed with $0.1 \%$ Trifluoroacetic acid (TFA), and then eluted with $80 \%$ acetonitrile and $0.1 \%$ TFA. The sample was dried down under nitrogen. ET was detected with the use of an $\left[{ }^{125} \mathrm{I}\right]$ ET-1 radioimmunoassay kit whose cross reactivity values were negligible with unrelated vasoactive peptides such as arginine vasopressin $(0.02 \%)$, angiotensin II $(0.03 \%)$, atrial natriuretic peptide $($ ANP $<0.01 \%)$, brain natriuretic peptide $(<0.01 \%)$ and big ET-1 (0.26\%), whereas it showed considerable cross-reactivity with other ET isopeptides such as ET-2 (144\%), ET-3 $(52 \%)$, sarafotoxin $6 \mathrm{~b}\left(\mathrm{~S}_{\mathrm{b}}, 12 \%\right)$ and vasoactive intestinal contractor $(100 \%)$. Although circulating plasma ET is contributed predominantly by ET-1, in view of the significant cross-reactivity of the ligand with ET-2 and ET-3 in the RIA procedure used in our study, the data obtained was stated as changes in plasma ET concentrations. Recovery of ET-1 was determined to be $79 \%$.

Tension measurements. Ring preparations of the thoracic aorta $(5 \mathrm{~mm})$ were dissected and cleared of adhering fat and connective tissues. Aortic segments were gently rubbed between thumb and forefinger to facilitate endothelium removal in those experiments requiring endothelial denudation. They were then set up for isometric tension measurements in $20 \mathrm{ml}$ organ baths containing modified Krebs physiological salt solution $\mathrm{KH}_{2} \mathrm{PO}_{4}$ (in mmol/l): $\mathrm{NaCl} \mathrm{118,} \mathrm{KCl} 4.7, \mathrm{KH}_{2} \mathrm{PO}_{4} 1.2$, $\mathrm{MgCl}_{2} \cdot 6 \mathrm{H}_{2} \mathrm{O} 1.2, \mathrm{CaCl}_{2} \cdot 2 \mathrm{H}_{2} \mathrm{O} 1.8, \mathrm{NaHCO}_{3} 25.0$, and glucose 11.1) and continuously oxygenated with $95 \% \quad \mathrm{O}_{2} / 5 \%$ $\mathrm{CO}_{2}$ at $37^{\circ} \mathrm{C}$. Maximal force development to ET-1 (100 nmol/ 1) was determined to be at $2 \mathrm{~g}$ resting preload tension in all groups (data not shown), thus preload was set at $2 \mathrm{~g}$. Increases in isometric tension at basal and agonist evoked conditions were recorded on a Grass 7E polygraph with FTO 3 force transducers. The detailed procedure for measuring tension development in aortic rings is described elsewhere [31].

The tissues were allowed to equilibrate for $1 \mathrm{~h}$ (with washings every $20 \mathrm{~min}$ ) before the tissue was made stable with a dose of phenylephrine $\left(3 \times 10^{-5} \mathrm{~mol} / \mathrm{l}\right)$. After allowing the tissue to return to baseline tension, methoxamine was added in a cumulative dose fashion after which acetylcholine chloridechallenge was done to assess endothelium integrity. All drugs were added in 50-100 $\mu \mathrm{l}$ quantities to provide the required final bath concentrations. The tissues were allowed to relax to baseline tension for $1 \mathrm{~h}$ after which cumulative dose additions were undertaken with ET-1. At the end of the experiment, tissues were allowed to dry overnight, weighed and the cross sectional areas were calculated as described to allow for expression of tension development in $\mathrm{g} \cdot \mathrm{mm}^{-2}$ [31].

Drugs and chemicals. Acetylcholine chloride, methoxamine hydrochloride, phenylephrine hydrochloride, sodium orthovanadate, and streptozotocin were obtained from Sigma-Aldrich (Milwaukee, Wis., USA). Human/porcine/rat endothelin1 (ET-1) was obtained from American Peptide Co Inc. (Sunnyvale, Calif., USA) and Iletin II insulin and sterile diluent were from Eli Lilly (Indianapolis, Ind., USA).

Data analysis. Cumulative concentration response curves to the drugs were analysed individually in order to express the concentration producing $50 \%$ maximum response $\left(\mathrm{EC}_{50}\right)$ and maximum response $\left(E_{\max }\right)$ values as mean $\pm S E M$. Sensitivity $\left(\mathrm{EC}_{50}\right)$ values were derived from log concentration response curves. Comparison of mean values amongst the various 
Table 1. Metabolic variables in STZ-induced diabetic and control group of Sprague-Dawley (SD) rats subjected to insulin $\left(12 \mathrm{mU} \cdot \mathrm{Kg}^{-1} \cdot \mathrm{min}^{-1}\right.$, s. c.) infusion for 2 weeks

\begin{tabular}{|c|c|c|c|c|c|}
\hline Group & $\begin{array}{l}\text { Body weight } \\
\text { before }(\mathrm{g})\end{array}$ & $\begin{array}{l}\text { Body weight } \\
\text { after }(\mathrm{g})\end{array}$ & $\begin{array}{l}\text { Food intake } \\
\left(\mathrm{g} \cdot \mathrm{rat}^{-1} \cdot \mathrm{day}^{-1}\right)\end{array}$ & $\begin{array}{l}\text { Blood glucose } \\
(\mathrm{mmol} / \mathrm{l})\end{array}$ & $\begin{array}{l}\text { Plasma insulin } \\
(\mathrm{pmol} / \mathrm{l})\end{array}$ \\
\hline SD-control & $380 \pm 10$ & $447 \pm 5$ & $31 \pm 1.2$ & $7.0 \pm 0.8$ & $678 \pm 130$ \\
\hline SD-insulin & $390 \pm 15$ & $469 \pm 11$ & $29 \pm 1.6$ & $5.4 \pm 1.2$ & $1835 \pm 266^{c}$ \\
\hline STZ-control & $271 \pm 11^{\mathrm{a}}$ & $256 \pm 16^{\mathrm{a}}$ & $49 \pm 1.0^{\mathrm{a}}$ & $31.4 \pm 1.4^{\mathrm{a}}$ & $104 \pm 16^{a}$ \\
\hline STZ-insulin & $285 \pm 14^{\mathrm{a}}$ & $361 \pm 15^{b}$ & $33 \pm 1.5^{\mathrm{c}}$ & $8.4 \pm 0.9^{c}$ & $1560 \pm 127^{\mathrm{c}}$ \\
\hline $\begin{array}{l}\text { Data are me } \\
\text { a } p<0.001 \text { v }\end{array}$ & D group & & $\begin{array}{l}{ }^{\mathrm{b}} p<0.01 \text { vs rest } \\
{ }^{\mathrm{c}} p<0.001 \text { vs res }\end{array}$ & $\begin{array}{l}\text { e untreated gro } \\
\text { ve untreated gr }\end{array}$ & \\
\hline
\end{tabular}

Table 2. Metabolic variables in STZ-induced diabetic and control group of Sprague-Dawley (SD) rats treated with vanadate (p.o., $0.5 \mathrm{mg} / \mathrm{ml}$ ) for 2 weeks

\begin{tabular}{|c|c|c|c|c|c|}
\hline Group & $\begin{array}{l}\text { Body weight } \\
\text { before }(\mathrm{g})\end{array}$ & $\begin{array}{l}\text { Body weight } \\
\text { after }(\mathrm{g})\end{array}$ & $\begin{array}{l}\text { Food intake } \\
\left(\mathrm{g} \cdot \mathrm{rat}^{-1} \cdot \mathrm{day}^{-1}\right)\end{array}$ & $\begin{array}{l}\text { Blood glucose } \\
(\mathrm{mmol} / \mathrm{l})\end{array}$ & $\begin{array}{l}\text { Plasma insulin } \\
(\mathrm{pmol} / \mathrm{l})\end{array}$ \\
\hline SD-control & $401 \pm 15$ & $490 \pm 12$ & $33 \pm 1.0$ & $7.6 \pm 0.6$ & $799 \pm 109$ \\
\hline SD-vandate & $390 \pm 15$ & $435 \pm 11$ & $25 \pm 1.0^{c}$ & $7.2 \pm 0.4$ & $1036 \pm 73$ \\
\hline STZ-control & $254 \pm 15^{\mathrm{a}}$ & $311 \pm 21^{\mathrm{a}}$ & $47 \pm 1.0^{\mathrm{a}}$ & $28.3 \pm 1.0^{\mathrm{a}}$ & $109 \pm 18^{\mathrm{a}}$ \\
\hline STZ-vandate & $268 \pm 11^{\mathrm{a}}$ & $274 \pm 14^{\mathrm{b}}$ & $26 \pm 0.6^{c}$ & $9.0 \pm 1.2^{\mathrm{c}}$ & $145 \pm 18^{\mathrm{a}}$ \\
\hline
\end{tabular}

groups and with time zero was performed by analysis of variance (ANOVA) (Superanova SAS Institute, San Francisco, Calif., USA). Simultaneous multiple comparisons were examined by Scheffe's $F$-test. Level of significance was defined as a $p$ value of less than 0.05 .

\section{Results}

Body weight and food intake of all groups before and after the 2 week insulin and vanadate treatment period are shown in Tables 1 and 2 respectively. The body weights of STZ rats before treatment (3 weeks postSTZ) were lower $(p<0.001)$ than in normal rats in all groups. Over the 2 week treatment period, untreated STZ rats failed to show a significant increase in body weight. STZ rats treated with vanadate also failed to show significant increases in weight over the treatment period and SD rats treated with vanadate gained significantly less weight than their untreated counterparts. These observations are in accordance with other studies showing that, under short term treatment ( $<20$ days) with vanadate, STZ rats tend to lose weight [32]. Insulin treated STZ rats, on the other hand, gained weight over the treatment period. Food intake over the 2 week treatment period was significantly greater in all untreated STZ rats than in all SD groups. Both vanadate and insulin treatment significantly lowered food intake in STZ rats to near that of untreated SD controls. Vanadate treatment also led to a significantly reduced food intake in SD rats. Vanadate intake, calculated by multiplying daily water intake by vanadate concentration in the water, amounted to $30 \pm 0.7 \mathrm{mg} \cdot \mathrm{rat}^{-1} \cdot \mathrm{day}^{-1}$ in STZ rats, and $22 \pm 1.3 \mathrm{~g} \cdot \mathrm{rat}^{-1} \cdot \mathrm{day}^{-1}$ in SD rats. This dose is in line with previous studies showing beneficial effects of vanadate on blood glucose concentrations [30, 32].

Blood glucose and plasma insulin concentrations for all groups are shown in Tables 1 and 2. Both untreated STZ groups had higher $(p<0.001)$ fasting plasma glucose and lower $(p<0.001)$ plasma insulin concentrations than SD controls. Insulin and vanadate treated STZ rats had lower $(p<0.001)$ blood glucose concentrations than untreated STZ rats. Vanadate treatment had no significant effect on plasma insulin concentrations in either STZ or SD rats, but as expected, insulin treatment raised $(p<0.001)$ plasma insulin concentrations in both groups. Plasma ET concentrations (pmol/l) as shown in Figure 1 were lower in untreated STZ groups than in untreated SD groups (untreated insulin group: SD, $1.04 \pm 0.20 ;$ STZ, $0.46 \pm 0.08, p<0.05$; untreated vanadate group: $\mathrm{SD}$, $1.05 \pm 0.18 ;$ STZ, $0.39 \pm 0.06, p<0.05)$. Both insulin and vanadate treated STZ rats had significantly higher plasma ET concentrations than untreated STZ rats (insulin group: untreated, $0.46 \pm 0.08$; treated, $1.09 \pm 0.19, p<0.05$; vanadate group: untreated, $0.39 \pm 0.06$; treated, $0.88 \pm 0.12, p<0.05)$. SD rats treated with vanadate or insulin also had increased plasma ET concentrations compared with untreated respective control groups (insulin group: untreated, $1.04 \pm 0.20$; treated, $1.94 \pm 0.12, p<0.05$; vanadate group: untreated, $1.05 \pm 0.18$; treated, $1.85 \pm 0.22$, $p<0.05$ ) (Fig. 1).

Tension response studies in aortic rings are shown in Figures 2 and 3. Maximum tension responses to ET-1 were greater $(p<0.01)$ in aortae from both un- 


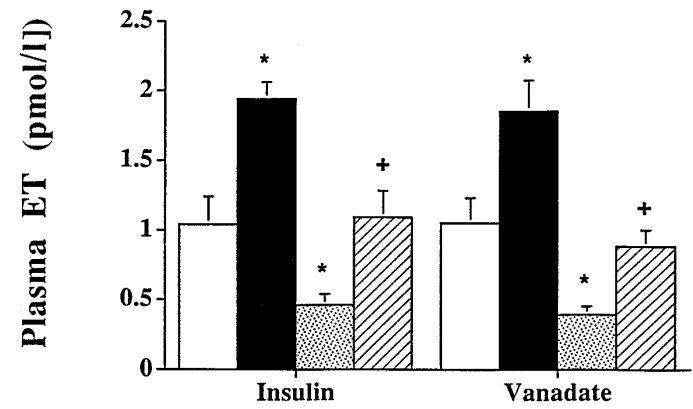

Fig. 1. Plasma ET (pmol/l) concentrations. SD-control $(\square)$,

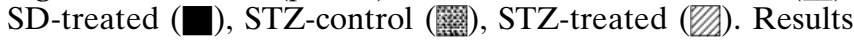
represent mean \pm SEM of eight separate determinations using plasma samples from eight different rats. ${ }^{*} p<0.05$ vs respective $\mathrm{SD}$-control; and $+p<0.05$ vs respective STZ-control
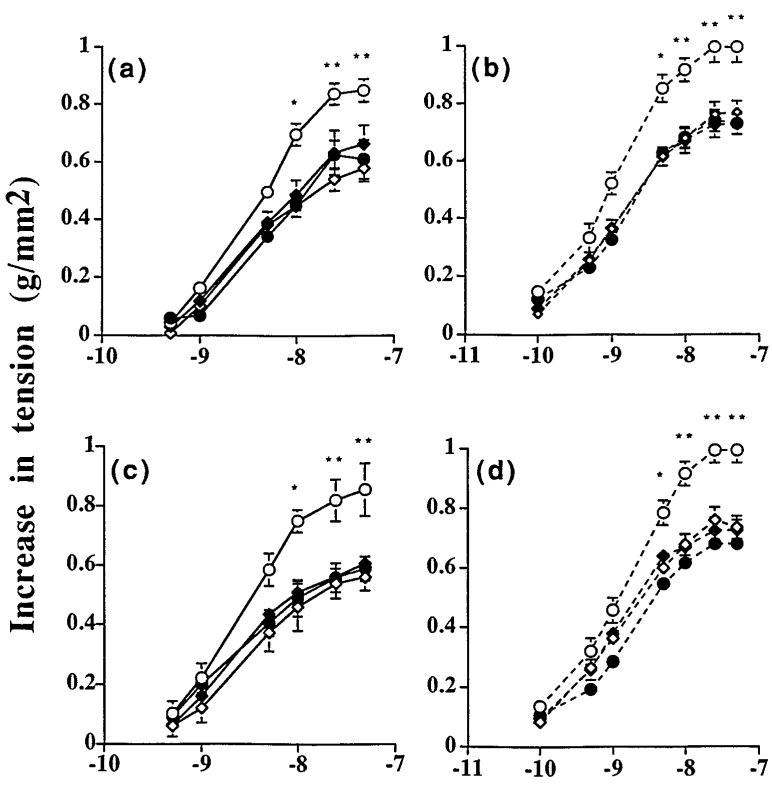

\section{Log molar ET-1}

Fig. 2a-d. Cumulative-concentration response curves to ET-1 $(0.1 \mathrm{nmol} / 1-50 \mathrm{nmol} / \mathrm{l})$ in ring preparations of rat aorta with intact and denuded endothelium in 5 week streptozotocin (STZ) diabetic rats and Sprague-Dawley (SD) non-diabetic rats treated or untreated with either insulin (s. c. $12 \mathrm{mU} \cdot \mathrm{kg}^{-1} \cdot \mathrm{min}^{-1}$ ) or sodium orthovanadate $(0.5 \mathrm{mg} / \mathrm{ml})$ in water ad libitum for two weeks. Line graphs for the upper panel - describes data from aortae of insulin group with intact $(-)$ (a) and denuded (----) (b) endothelium. Line graphs from the lower panel depict data from aortae from vanadate treated group with intact (c) and denuded $(\mathbf{d})$ endothelium: SD-untreated $(\diamond)$, SD-treated $(\diamond)$, STZ-untreated $(\bigcirc)$, and STZ-treated $(\bigcirc)$ rats. Each data point is a mean \pm SEM of eight separate determinations using tissues from eight different rats. $* p<0.05, * * p<0.01$ in comparison with same data point for all other groups treated groups of STZ rats than in their non-diabetic counterparts both in the presence (Fig. $2 \mathrm{a}, \mathrm{c}$ ) and absence (Fig. 2b,d) of intact endothelium. Aortae from insulin (upper panel Fig. $2 \mathrm{a}, \mathrm{b}$ ) and vanadate (lower panel Fig. 2c,d) treated STZ rats, however, showed maximum ET-1 evoked tension responses similar to those in untreated SD rats. There was no difference in maximum tension development in insulin and vanadate treated SD groups when compared with untreated SD controls, again both in the presence and absence of endothelium. Also, there were no differences in $\mathrm{EC}_{50}$ values amongst any of the groups with the exception of endothelium removal which resulted in a shift to the left in the cumulative concentration response curves to ET-1 in all groups with no changes in $E_{\max }$ values (Fig. 2c,d and Table 3). Similarly, methoxamine evoked increases in maximum tension development were greater $(p<0.01)$ in untreated STZ rats compared with SD controls both in the presence (Fig. 3a,c) and absence (Fig. 3 b,d) of intact endothelium, and both insulin (Fig. $3 \mathrm{a}, \mathrm{b}$ ) and vanadate (Fig. 3c,d) treatment appeared to correct this abnormality to the level of normal controls. Once again, no differences in $\mathrm{EC}_{50}$ values were observed amongst any of the groups with the exception of endothelium denuded groups exhibiting a shift to the left in the cumulative concentration response curves to methoxamine with no significant changes in $\mathrm{E}_{\max }$ values (Fig. 3 c,d and Table 3).

\section{Discussion}

Our study shows that 5 weeks of STZ-induced diabetes is associated with decreased plasma ET concentrations and exaggerated ET-1 evoked vasoconstrictor responses. Oral vanadate treatment and continuous subcutaneous delivery of insulin for 2 weeks led to: a) a significant decrease in fasting plasma glucose to non-diabetic concentrations in STZ rats, b) restoration of decreased plasma ET concentrations in STZ diabetic rats to that of the controls, c) raising of plasma ET concentrations by about twofold in normal SD rats, and d) returning increased $\mathrm{E}_{\max }$ to vasoconstrictor agonists to normal in STZ rats. We have shown for the first time that short-term (2 weeks) insulin and vanadate treatment leads to higher plasma ET concentrations and prevents or reverses the exaggerated vasoconstrictor responses to ET-1 in STZ diabetic rats.

The role of ET in the diabetic state is controversial. Hyperlipidaemia, hyperglycaemia, and hyperinsulinaemia are all thought to alter plasma concentrations of ET in the diabetic state [23-26, 33], but the direction of changes in plasma ET in diabetes is uncertain. In contrast to our observation of decreased plasma ET concentrations in STZ rats, some studies have shown increased plasma ET in STZ rats and pa- 


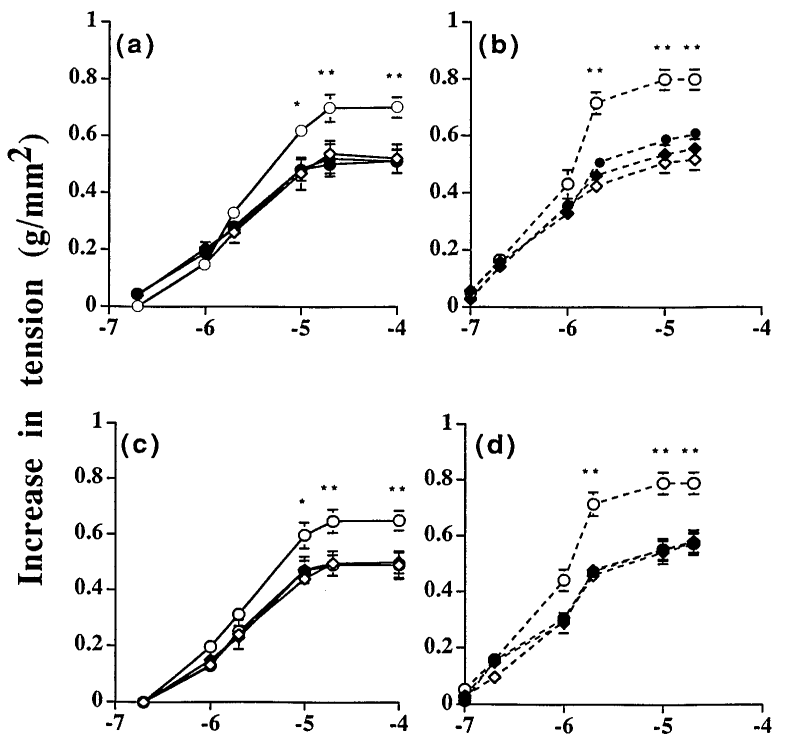

Log molar methoxamine

Fig.3a-d. Cumulative-concentration response curves to methoxamine $(100 \mathrm{nmol} / \mathrm{l}-100 \mu \mathrm{mol} / \mathrm{l})$ in rat aortic ring preparations. Upper panel - aortae from insulin group with intact (-) (a) and denuded (- - -) (b) endothelium. Lower panel - aortae from vanadate group with intact (c) and denuded (d) endothelium: SD-untreated $(\diamond)$, SD-treated $(\diamond)$, STZ-untreated $(\bigcirc)$, and STZ-treated $(O)$ rats. Each data point is a mean \pm SEM of eight separate determinations using tissues from eight different rats. $* p<0.05 ; * * p<0.01$ in comparison with same data point for all other groups

tients with Type I diabetes [4, 15, 17-19]. On the other hand, in support of our observations, significantly lower plasma ET concentrations in Type I diabetic patients and undetectable ET immunoreactivity in plasma of STZ rats have also been reported [20-22]. Similarly, in vitro studies with cultured bovine or porcine aortic EC have shown both elevated and decreased concentrations of ET released after addition of high glucose to the culture medium $[24,33]$. Discrepancies in vivo may result from differences in the degree and duration of hyperglycaemia, the presence of diabetic complications, and possibly in the state of endothelial function in the model studied. It is possible that differences in endothelium derived relaxing factor (EDRF) production may contribute to these variations since its function declines in proportion to the duration of hyperglycaemia in STZ diabetes, and it is known to inhibit ET release [12, 34]. Acetylcholine-evoked relaxation of aortic rings was intact in our study (data not shown), suggesting that EDRF production remained unaffected by STZ diabetes in this vascular smooth muscle preparation. Thus, it may be that unaltered EDRF production along with diminished plasma insulin concentrations in the untreated STZ group resulted in decreased ET production since insulin is well known to stimulate ET release from vascular EC [23]. Longer term STZ rats may exhibit augmented ET-1 concentrations secondary to endothelial dysfunction and attenuated EDRF production.

The observation that insulin treatment restores plasma ET concentrations to normal in STZ rats and increases it twofold in normal control rats can be explained by its cellular actions on EC. In 1991, using cultured bovine aortic EC, it was shown that insulin $(1.6 \mathrm{nmol} / \mathrm{l})$ increased prepro ET mRNA concentrations within $2 \mathrm{~h}$ and a maximum effect was reached at $17 \mathrm{nmol} / 1$ [23]. Later studies have shown that insulin infusion increases plasma ET concentrations in humans $[25,26]$. The increase in plasma ET after insulin treatment of diabetic rats in our study could be due to: a) the return to normal of hyperglycaemia and hyperlipidaemia resulting in restoration of ET production from EC [26], b) the return to normal of hyperglycaemia leading to restoration of EDRF mediated inhibition of ET release [12,34] or c) the direct effect of insulin on endothelial ET production [23,24]

Table 3. Sensitivity $\left(\mathrm{EC}_{50}\right)$ and maximum response $\left(\mathrm{E}_{\max }\right)$ variables in isolated aortic rings of treated and untreated STZ and SD rats

\begin{tabular}{|c|c|c|c|c|c|c|c|c|}
\hline \multirow[t]{3}{*}{ Group } & \multicolumn{4}{|c|}{ Endothelium intact } & \multicolumn{4}{|c|}{ Endothelium denuded } \\
\hline & \multicolumn{2}{|c|}{ Methoxamine } & \multicolumn{2}{|l|}{ ET-1 } & \multicolumn{2}{|c|}{ Methoxamine } & \multicolumn{2}{|l|}{ ET-1 } \\
\hline & $\begin{array}{l}\mathrm{EC}_{50} \\
(\mu \mathrm{mol} / \mathrm{l})\end{array}$ & $\begin{array}{l}\mathrm{E}_{\max } \\
\left(\mathrm{g} / \mathrm{mm}^{2}\right)\end{array}$ & $\begin{array}{l}\mathrm{EC}_{50} \\
(\mathrm{nmol} / \mathrm{l})\end{array}$ & $\begin{array}{l}\mathrm{E}_{\max } \\
\left(\mathrm{g} / \mathrm{mm}^{2}\right)\end{array}$ & $\begin{array}{l}\mathrm{EC}_{50} \\
(\mu \mathrm{mol} / \mathrm{l})\end{array}$ & $\begin{array}{l}\mathrm{E}_{\max } \\
\left(\mathrm{g} / \mathrm{mm}^{2}\right)\end{array}$ & $\begin{array}{l}\mathrm{EC}_{50} \\
(\mathrm{nmol} / \mathrm{l})\end{array}$ & $\begin{array}{l}\mathrm{E}_{\max } \\
\left(\mathrm{g} / \mathrm{mm}^{2}\right)\end{array}$ \\
\hline \multicolumn{9}{|c|}{ Insulin $\left(12 \mathrm{mU} \cdot \mathrm{Kg}^{-1} \cdot \mathrm{min}^{-1}\right)$ s.c. $\times 2$ weeks } \\
\hline SD-control & $2.00 \pm 0.06$ & $0.54 \pm 0.05$ & $2.90 \pm 0.03$ & $0.58 \pm 0.05$ & $0.72 \pm 0.04^{\mathrm{c}}$ & $0.52 \pm 0.04$ & $1.20 \pm 0.08^{\mathrm{c}}$ & $0.77 \pm 0.04$ \\
\hline SD-treated & $1.70 \pm 0.02$ & $0.51 \pm 0.04$ & $3.50 \pm 0.05$ & $0.66 \pm 0.07$ & $0.83 \pm 0.05^{\mathrm{c}}$ & $0.56 \pm 0.03$ & $1.20 \pm 0.07^{\mathrm{c}}$ & $0.73 \pm 0.03$ \\
\hline STZ-control & $2.30 \pm 0.04$ & $0.70 \pm 0.04^{\mathrm{a}}$ & $4.00 \pm 0.06$ & $0.85 \pm 0.04^{\mathrm{a}}$ & $0.83 \pm 0.04^{\mathrm{c}}$ & $0.80 \pm 0.04^{\mathrm{a}}$ & $1.00 \pm 0.05^{\mathrm{c}}$ & $0.99 \pm 0.05^{\mathrm{a}}$ \\
\hline STZ-treated & $1.80 \pm 0.04$ & $0.52 \pm 0.05^{\mathrm{b}}$ & $5.50 \pm 0.07$ & $0.63 \pm 0.07^{b}$ & $0.83 \pm 0.07^{\mathrm{c}}$ & $0.60 \pm 0.03^{\mathrm{b}}$ & $1.20 \pm 0.06^{\mathrm{c}}$ & $0.73 \pm 0.04^{b}$ \\
\hline \multicolumn{9}{|c|}{ Vanadate $(0.5 \mathrm{mg} / \mathrm{ml})$ p.o. $\times 2$ weeks } \\
\hline SD-control & $2.50 \pm 0.03$ & $0.50 \pm 0.04$ & $2.40 \pm 0.03$ & $0.56 \pm 0.05$ & $0.90 \pm 0.06^{\mathrm{c}}$ & $0.57 \pm 0.04$ & $1.00 \pm 0.05^{\mathrm{c}}$ & $0.73 \pm 0.04$ \\
\hline SD-treated & $2.30 \pm 0.02$ & $0.50 \pm 0.04$ & $2.50 \pm 0.04$ & $0.61 \pm 0.02$ & $0.90 \pm 0.05^{\mathrm{c}}$ & $0.58 \pm 0.04$ & $1.00 \pm 0.04^{\mathrm{c}}$ & $0.73 \pm 0.03$ \\
\hline STZ-control & $2.20 \pm 0.05$ & $0.65 \pm 0.04^{\mathrm{a}}$ & $2.60 \pm 0.03$ & $0.86 \pm 0.09^{\mathrm{a}}$ & $0.75 \pm 0.08^{c}$ & $0.79 \pm 0.04^{\mathrm{a}}$ & $1.15 \pm 0.08^{\mathrm{c}}$ & $0.99 \pm 0.04^{\mathrm{a}}$ \\
\hline STZ-treated & $2.10 \pm 0.02$ & $0.49 \pm 0.05^{\mathrm{b}}$ & $2.10 \pm 0.04$ & $0.59 \pm 0.04^{\mathrm{b}}$ & $0.90 \pm 0.07^{\mathrm{c}}$ & $0.57 \pm 0.04^{\mathrm{b}}$ & $1.15 \pm 0.07^{\mathrm{c}}$ & $0.68 \pm 0.03^{b}$ \\
\hline
\end{tabular}

Data are mean \pm SEM performed using tissues obtained from eight rats for each group.

${ }^{\mathrm{a}} p<0.01$ vs untreated SD group, ${ }^{\mathrm{b}} p<0.01$ vs untreated STZ group, ${ }^{\mathrm{c}} p<0.01$ vs same point with endothelium intact 
or an interplay of these events. The observation that vanadate increases plasma ET in a manner similar to insulin in both STZ and normal rats is novel but it is known to mimic most of the cellular and metabolic actions of insulin via inhibition of protein tyrosine phosphatases, leading to enhanced insulin sensitive and non-sensitive tyrosine kinase activation [30]. Thus, vanadate may enhance plasma ET concentrations in a manner similar to the mechanism whereby insulin increases ET release.

In our study, vanadate treatment led to reduced food intake in both normal and diabetic rats. Earlier it has been shown that the hypophagic effect of vanadate is only transient [32]. No studies to date have assessed the effect of hypophagia on plasma ET concentrations in normal or diabetic states. There are three points we should mention: a) vanadium compounds both in vivo and in vitro mimic most, if not all of the metabolic actions of insulin, b) in the present study, both insulin and vanadate evoke similar effects on ET-1 action, and c) it is now well established that the effects of vanadate on metabolic variables are separate from its effects on hypoghagia [30]. It is thus improbable that reduced food intake in the vanadate groups contributed to alterations in plasma ET.

Although our study suggests that STZ diabetes is associated with increases in vasoconstrictor responses to both ET-1 and MTX, other studies have shown both decreased $[9,15,17]$ and increased $[10,13]$ vasoconstrictor and vasodilator responses to ET-1 and both decreased $[7,11]$ and increased $[8,12,14]$ vasoconstrictor responses to $\alpha_{1}$ adrenergic stimulation in STZ rats. This interstudy variation could result from differences in the vascular bed studied, the severity and duration of hyperglycaemia and differences in experimental procedures for measuring vasoconstriction [1]. Some studies showing increased vasoconstrictor responses in STZ diabetic rats to various agonists have shown the increase to be of a non-specific nature leading to enhanced vasoconstriction regardless of the agonist used $[1,8]$. Our observation that plasma ET concentrations are decreased in STZ rats suggests ET receptor up-regulation as a potential mechanism whereby responses to ET-1 ex vivo would be enhanced. A recent study has shown desensitized $\mathrm{ET}_{\mathrm{A}}$ mediated vasoconstrictor and $\mathrm{ET}_{\mathrm{B}}$ mediated vasodilator responses in the perfused mesenteric vascular bed along with raised plasma ET-1 in 10-week-old STZ diabetic rats [17]. These results suggest that raised ET induced receptor down regulation could have contributed to desensitized ET evoked vascular responses. In our study, although we cannot rule out receptor changes due to attenuated ET concentrations, it is probable that another common mechanism is responsible for higher reactivity to ET-1. This is supported by both MTX and ET-1 evoked vasoconstrictor responses being enhanced (non-specific ef- fect), both in the presence and absence of intact endothelium (endothelium independent). Alterations in metabolic variables such as plasma lipids, glucose, and insulin concentrations could all potentially contribute to alterations in vascular smooth muscle function in STZ diabetes [1], leading to a generalized enhancement of the contractile state of the vasculature.

Insulin treatment has been shown to return altered contractile responses in the STZ diabetic rat to normal $[7,16]$. Furthermore, in addition to its well-established insulinomimetic effects on metabolic abnormalities in the STZ rat [30], at least one group has shown oral vanadate therapy to improve vascular reactivity in STZ rats [14]. In this study, however, the effect of long-term (10 weeks) treatment was assessed and neither responses to ET-1 nor comparisons to insulin were undertaken. Given increasing evidence that metabolic abnormalities are a major causative factor in diabetic vascular complications - and the fact that they are reversible by insulin treatment and restoration of metabolic control, it is likely that the beneficial effects of these compounds are mediated by correction of metabolic variables in the STZ rat $[1,7,16]$. Furthermore, since exaggerated responses are corrected in both endothelial denuded and intact aorta, it is likely that correction of abnormal vascular responses in the STZ rats occurs at the vascular smooth muscle level.

ET-1 is a potent endothelial derived vasoconstrictor and mitogenic peptide [35]. Its potency and longlasting effects suggest that it is an integral component involved in the local control of blood flow to all organs of the body. Altered ET-1 action [5, 6], and raised plasma ET [2-5] have been observed in several cardiovascular disease states. Despite the fact that ET is known mainly as a paracrine hormone [36], plasma concentrations of ET are thought to parallel concentration of ET released in a paracrine manner by the vascular endothelium [3]. The observation that STZ diabetes leads to alterations in plasma ET and action at the level of vascular smooth muscle suggests ET as a contributor to the vascular complications observed in this animal model of Type I diabetes. The restoration by insulin and vanadate treatment of these indices of ET activity to normal in the diabetic state provides further evidence of the beneficial vascular effects of these compounds.

We and others have shown that insulin per se is able to up regulate $\mathrm{ET}_{\mathrm{A}}$ receptors in aortic smooth muscle cells in vitro $[27,28]$. Furthermore, we have recently observed that aortic tissue from hyperinsulinaemic-insulin resistant obese Zucker rats had increased $\mathrm{ET}_{\mathrm{A}}$ receptor concentrations [28]. Thus, it is possible that insulin has the capability to regulate not only ET peptide expression but also, at higher concentrations, to regulate ET receptor expression in vivo. Thus, along with vascular smooth muscle mitogenic [37] and other hypertension-promoting ef- 
fects [38], it is possible that high plasma insulin can promote adverse cardiovascular events via augmented ET activity at the vascular smooth muscle level. The observation that vascular complications still arise in diabetic patients despite adequate glucose control supports the concept that insulin treatment can promote adverse vascular complications [39]. Our study shows, however, that poor metabolic control associated with hypoinsulinaemia can also promote a general enhancement of vascular reactivity as well as alterations in ET plasma concentrations. Thus, tight metabolic control of insulin-dependent diabetes (minimizing fluctuations between insulinaemia and glycaemia/ lipidaemia) is essential to prevent potential ET mediated cardiovascular complications in this metabolic disorder.

While vanadium compounds represent an orally bioavailable insulinomimetic alternative with great potential for the treatment of Type I diabetes, they have well-established gastrointestinal, renal and cardiovascular toxicities per se [30, 40, 41]. Thus, despite the return to normal of ET action by insulin and vanadate treatment via correction of metabolic abnormalities, considerable limitations exist in the use of these agents in Type I diabetes.

In conclusion, our results show that 5-week STZ diabetic rats had enhanced agonist-evoked vasoconstrictor responses and decreased plasma ET relative to non-diabetic controls. Both insulin and vanadate treatment of STZ rats for 2 weeks returns these alterations to normal. Since recent research has focused on metabolic abnormalities as a major causative factor in diabetic vascular complications [1, 29, 39], the beneficial effects of insulin and vanadate on metabolic control suggests a beneficial effect on adverse cardiovascular alterations in STZ diabetes treated with these compounds. Despite potential atherogenic and hypertensiogenic effects, insulin and vanadate treatment in Type I diabetes can beneficially affect alterations in vascular ET activity present in the STZ diabetic rat.

Acknowledgements. This work was supported by grants-in-aid from the Medical Research Council of Canada and the Heart \& Stroke Foundation of Saskatchewan.

\section{References}

1. Tomlinson KC, Gardiner SM, Hebden RA, Bennett T (1992) Functional consequences of streptozotocin induced diabetes mellitus, with particular reference to the cardiovascular system. Pharmacol Rev 44: 103-150

2. Tomita K, Ujiie K, Nakanishi T et al. (1989) Plasma endothelin levels in patients with acute renal failure. $\mathrm{N}$ Eng $\mathrm{J}$ Med 321: 1127

3. Lerman A, Edwards BS, Hallet JW, Heublein DM, Sandberg SM, Burnett JC (1991) Circulating and tissue endothelin immunoreactivity in advanced atherosclerosis. $\mathrm{N}$ Eng $\mathrm{J}$ Med 325: 997-1001
4. Haak T, Jungmann E, Felber A, Hillmann U, Usadel KH (1992) Increased plasma levels of endothelin in diabetic patients with hypertension. Am J Hypertens 5: 161-166

5. Luscher TF, Seo BG, Buhler FR (1993) Potential role of endothelin in hypertension. Hypertension 21: 752-757

6. Batra VK, McNeill JR, Xu Y, Wilson TW, Gopalakrishnan $\mathrm{V}$ (1993) $\mathrm{ET}_{\mathrm{B}}$ receptors on aortic smooth muscle cells of spontaneously hypertensive rats. Am J Physiol 264:C479_ C484

7. Pfaffman MA, Ball CR, Darby A, Hilman R (1982) Insulin reversal of diabetes induced inhibition of vascular contractility in the rat. Am J Physiol 242:H490-H495

8. White RE, Carrier GO (1990) Vascular contraction induced by activation of membrane calcium ion channels is enhanced in streptozotocin diabetes. J Pharmacol Exp Ther 253: 1057-1062

9. Fulton DJ, Hodgson WC, Sikorski BW, King RG (1991) Attenuated responses to endothelin-1, $\mathrm{KCl}$, and $\mathrm{CaCl}_{2}$, but not noradrenaline of aortae from rats with streptozotocin induced diabetes mellitus. Br J Pharmacol 104: 928-932

10. Kiff RJ, Gardiner SM, Compton AM, Bennett T (1991) The effects of endothelin-1 and NG-nitro-L-arginine meth$y l$ ester on regional haemodynamics in conscious rats with streptozotocin induced diabetes mellitus. Br J Pharmacol 103: $1321-1326$

11. Cameron NE, Cotter MA (1992) Impaired contraction and relaxation in aorta from streptozotocin diabetic rats - role of polyol pathway. Diabetologia 35: 1011-1019

12. Chang KS, Stevens WC (1992) Endothelium dependent increase in vascular sensitivity to phenylephrine in long term streptozotocin diabetic rat aorta. Br J Pharmacol 107: 983-990

13. Tammesild PJ, Hodgson WC, King RG (1992) Increased sensitivity to endothelin-1 in isolated Kreb's-perfused kidneys of streptozotocin diabetic rats. Clin Exp Pharmacol Physiol 19: 261-265

14. Ozcelikay AT, Pekiner C, Ari N, Ozturk Y, Ozuari A, Altan VM (1994) The effect of vanadyl treatment on vascular responsiveness of streptozotocin diabetic rats. Diabetologia 37: 572-578

15. Tada H, Muramatsu I, Nakai T, Kigoshi S, Miyabo S (1994) Effects of chronic diabetes on the responsiveness to endothelin and other agents of rat atria and thoracic aorta. Gen Pharmacol 25: 1221-1228

16. Heygate KM, Davies J, Holmes M, James RF, Thurston H (1996) The effect of insulin treatment and of islet transplantation on the resistance artery function in the STZ-induced diabetic rat. Br J Pharmacol 119: 495-504

17. Makino A, Kamata K (1998) Elevated plasma endothelin-1 level in streptozotocin induced diabetic rats and responsiveness of the mesenteric arterial bed to endothelin- 1 . Br J Pharmacol 123: 1065-1072

18. Takahashi K, Ghatei MA, Lam HC, O'Hallaran DJ, Bloom SR (1990) Elevated plasma endothelin in patients with diabetes mellitus. Diabetologia 33: 306-310

19. Takeda Y, Miyamori I, Yoneda T, Takeda R (1991) Production of endothelin-1 from the mesenteric arteries of streptozotocin induced diabetic rats. Life Sciences 48: 2553-2556

20. Smulders RA, Stehouwer CD, Olthof CG et al. (1994) Plasma endothelin levels and vascular effects of intravenous L-arginine infusion in subjects with uncomplicated insulin-dependent diabetes mellitus. Clin Sci (Colch) 87: $37-43$

21. Malamitsi-Puchner A, Economou E, Katsouyanni K, Karachaliou F, Delis D, Bartsocas CS (1996) Endothelin 1-21 plasma concentrations in children and adolescents with in- 
sulin dependent diabetes mellitus. J Pediatr Endocrinol Metab 9(4):463-468

22. Takahashi K, Suda K, Lam HC, Ghatei MA, Bloom SR (1991) Endothelin like immunoreactivity in rat models of diabetes mellitus. J Endocrinol 130: 123-127

23. Oliver FJ, De La Rubia G, Feener EP et al. (1991) Stimulation of endothelin-1 gene expression by insulin in endothelial cells. J Biol Chem 266: 23251-23256

24. Hattori Y, Kasai K, Nakamura T, Emoto T, Shimoda S (1991) Effect of glucose and insulin on immunoreactive endothelin release from cultured porcine aortic endothelial cells. Metabolism 40: 165-169

25. Ferri C, Pittoni V, Piccoli A et al. (1995) Insulin stimulates endothelin-1 secretion from human cultured endothelial cells and modulates its circulating levels in vivo. J Clin Endocrinol Metab 80: 829-835

26. Piatti PM, Monti LD, Conti M et al. (1996) Hypertriglyceridemia and hyperinsulinemia are potent inducers of endothelin release in humans. Diabetes 45: 316-321

27. Frank HJ, Levin ER, Hu RM, Pedram A (1993) Insulin stimulates endothelin binding and action on cultured vascular smooth muscle cells. Endocrinology 133: 1092-1097

28. Hopfner RL, Hasnadka RV, Wilson TW, McNeill JR, Gopalakrishnan V (1998) Insulin increases endothelin-1 evoked $\left[\mathrm{Ca}^{2+}\right]_{\mathrm{i}}$ responses by increased $\mathrm{ET}_{\mathrm{A}}$ receptor expression in rat aortic smooth muscle cells. Diabetes 47: 937-944

29. Diabetes Control and Complications Trial Research Group (1993) The effect of intensive treatment of diabetes on the development and progression of long term complications in insulin dependent diabetes mellitus. N Eng J Med 329: 977-986

30. Brichard SM, Henquin JC (1995) The role of vanadium in the management of diabetes. Trends Pharmacol Sci 16: 265-270
31. Chen L, McNeill JR, Wilson TW, Gopalakrishnan V (1995) Differential effects of phosphoramidon on contractile responses to angiotensin II in rat blood vessels. Br J Pharmacol 114: 1599-1604

32. Becker DJ, Ongemba LN, Henquin JC (1994) Comparison of the effects of various vanadium salts on glucose homeostasis in streptozotocin diabetic rats. Eur J Pharmacol 260: 169-175

33. Yamauchi T, Ohnaka K, Takayanagi R, Umeda F, Nawata H (1990) Enhanced secretion of endothelin-1 by elevated glucose levels from cultured bovine aortic endothelial cells. FEBS Lett 267: 16-18

34. Boulanger CM, Luscher TF (1990) Release of endothelin from the porcine aorta. Inhibition by endothelium derived nitric oxide. J Clin Invest 85: 587-590

35. Yanagisawa M, Kurihara H, Kimura et al. (1988) A novel potent vasoconstrictor peptide produced by vascular endothelial cells. Nature 332: 411-415

36. Vane JR, Anggard EE, Botting RM (1990) Regulatory functions of the vascular endothelium. N Eng J Med 323: 27-36

37. Stout RW (1991) Insulin as a mitogenic factor: role in pathogenesis of cardiovascular disease. Am J Med 90:62S-65S

38. Scherrer U, Sartori C (1997) Insulin as a vascular and a sympathoexcitatory hormone. Circulation 96: 4104-4113

39. Kroc Collaborative Study Group (1984) Blood glucose control and the evolution of diabetic retinopathy and albuminuria. A preliminary multicentre trial. N Eng J Med 311: 365-372

40. Boscolo P, Carmignani M, Volpe AR et al. (1994) Renal toxicity and arterial hypertension in rats chronically exposed to vanadate. Occup Environ Med 51: 500-503

41. Sandirasegarane L, Gopalakrishnan V (1995) Vanadate increases cytosolic free calcium in rat aortic smooth muscle cells. Life Sci 56:PL169-PL174 